\title{
Implications of the Intertwined Effects of Curriculum Inclusive MOOCs
}

\author{
Aakarsh Shrivastava, Nitasha Hasteer, and K. M. Soni
}

\begin{abstract}
Massive open online courses have been popular among learners when it comes to technology-enhanced learning. With the high potential to enhance and drastically improve the learning process of the learners, MOOCs can conveniently be considered to offer blended e-learning for regular and traditional methods of learning. Universities are considering the adoption of these MOOCs by implementing different models to merge these MOOCs into the traditional classroom and regular curriculums. Multiple methods have been identified by various Universities for blended MOOCs. One such model is Curriculum Inclusive MOOC (ciMOOC) which is a framework implemented by a private Indian University to provide flexibility to both University and its students. The paper highlights the intertwined effects of the ciMOOC and records the perception of learners towards such blended models. Comparative of the evaluation methodologies adopted by the University for Curriculum Inclusive Model and the one used by a MOOC platform has been outlined. By analyzing the performance of learners in ciMOOC, the study attempts to evaluate the effectiveness of a blended model. From the analysis, we infer that a blended model of this nature reduces contact hours and facilitates the learning process.
\end{abstract}

Index Terms-Blended models of learning, evaluation criteria, MOOC, university, education.

\section{INTRODUCTION}

The development of the e-Learning platform has increased the diffusion of IT infrastructure in facilitating education amongst learners. MOOC is the most preferred term when e-Learning is taken into consideration. An IEEE CS 2022 report points out the potential of the Massive Open Online Courses (MOOCs) to revolutionize the world by 2022 [1]. The term MOOC was initially coined by the instructor of the first online course- Dave Cormier and Bryan Alexander [2].

In recent times, Universities and Colleges have been trying to explore blended models of learning where they focus on using IT infrastructure and e-Learning techniques in traditional learning methods. It is however not necessary that a blended model revolves around MOOCs but there has been a growth in interest of blending MOOCs to the traditional learning methods so that it can act as a complementary resource in achieving student-centric and instructor centric goals [3]. Blended MOOCs focus on providing

Manuscript received July 1, 2020; revised January 25, 2021.

Aakarsh Shrivastava is with the Department of IT, Amity School of Engineering and Technology, Amity University Uttar Pradesh, India (e-mail: aakarsh1996@hotmail.com).

Nitasha Hasteer is with Amity School of Engineering and Technology, Amity University Uttar Pradesh, India (e-mail: nitasha78@gmail.com).

K. M. Soni is with Amity University Uttar Pradesh, India (e-mail: kmsoni@yahoo.com). student-centered learning, effective assessment, bringing the benefits of face to face interaction in a MOOC environment, effective feedback, and also supporting the interactive design and video lectures considering the patterns of participants. Talking about the Indian scenario, from 2017, the Indian Government had allowed colleges and universities to offer up to $20 \%$ of their course material through the government MOOCs platform called Swayam which is a portal and integrated program for online courses [4]. In 2018, the University Grants Commission of India also known as UGC asked the Indian Colleges and Universities to adopt high-quality MOOCs. As the courses and curriculums of MOOCs are announced by NPTEL and Swayam in advance, the institutions are asked to select the most suitable courses for their students in the forthcoming semester. The freedom to offer a course in addition to the regular curriculum, in exchange for an existing course, or blend it with an existing course lies with the Institution.

In consideration of the increasing popularity and effectiveness of the open online courses, a blended model was implemented in a private Indian University in a computer science discipline and the framework was termed as curriculum inclusive MOOC (ciMOOC) [5]. The course was run across a semester i.e. for 6 months, which was a 4 credit ciMOOC offered by the university to its students for one particular semester. NPTEL was the MOOC platform taken into consideration [6]. Our study is focused on examining the effectiveness of the ciMOOCs which is integrated to the course curriculum in a private Indian University. Comparative is done of the methodologies for performance evaluation used by the University and MOOC platform in this particular model. A Systematic Literature review relevant to the area of study has been done and presented in Section II. The focus of the literature review was to determine the research directions and trends in blended MOOCs. Indicators of performance and design of the study is discussed in Section III and IV respectively. Analysis has been presented in Section V of the paper. The Implications are discussed in Section VI and Conclusions are drawn in Section VII.

\section{LITERATURE REVIEW}

The literature review of the studies elaborates upon the trends in blending the MOOCs with the curriculum of the educational institutions. These studies are categorised into three categories. The first one is general in nature that includes studies that depict general trends and how the research is progressing in blended MOOCs. It highlights an overview of MOOCs in the direction of the blended model. 
The second category elaborates upon various blended models proposed or has been put to practice by integrating curriculum with the MOOCs at a higher education institution. This category also expands upon how effective these models were and also the issues these models faced. The last category elaborates upon the concept of the curriculum inclusive MOOCs as our primary objective for this study is to analyze the performance and perception of learners in ciMOOC.

\section{A. State of the Art}

A study by W. Al-Rahmi et al. pointed out that the during the higher education, the academic performance of the students can be enhanced by using MOOCs as they facilitate self-learning by enhancing information sharing and providing relevant study material [7]. R. Chakravarty et al. in a study claimed that MOOCs won't be able to replace the traditional learning methods and practices used for teaching and learning because of the highly interactive nature of a traditional classroom [8]. Laia Albó et al. pointed out in a study that MOOCs blended with the curriculum were highly accepted by the teachers but lack of design projects in courses like electronics was a major problem. The same study also pointed out a lack of institutional support, lack of self-discipline amongst students, and rights of authorship as few of the major challenges in the implementation of various models of blended MOOCs [9]. Taghreed Alghamdi et al. categorized blended models of MOOCs into two categories, one was the supplementary model which basically uses MOOCs as an additional resource for students to revise and practice topics already covered in the classrooms, and the other was the integrated model where the universities integrate their curriculum with MOOCs and it's a compulsory course [10]. A study by Yue Li et al. highlighted that majority of the universities don't have any mechanism for credit transfer when it comes to MOOCs [11]. In a study, Sajid Iqbal et al. pointed out the lack of awarding credits and laboratory experience as a few of the major problems when engineering education was blended with MOOCs. In addition, the study also pointed out plagiarism and cheating were major challenges when awarding credit transfer for the MOOC [12].

\section{B. Blended MOOCs (bMOOCs)}

San Jose University first adopted the concept of blended MOOCs where it offered MOOCs-for-credit in a venture with Udacity, a popular MOOC platform. This collaboration started the concept of blending MOOCs with regular classrooms back in January 2013 [13]. In a study by J. Kay et al. it was highlighted that the Institutions are merging their Learning management systems with quality MOOCs to ensure that the professors can save the resources by making pre-recorded video lectures and course material available for the students online to ensure that the time of the traditional class can be utilized for problem-solving by tutorials and discussions [14]. Tayeb Brahimi et al. in their study pointed out the use of MOOCs by teachers for flipping the traditional classroom which had a promising impact on the enhancement of student's learning [15]. Antonia Bralić et al. highlighted that the students were given the option of opting for MOOCs instead of doing project work which had a positive impact on their performances [3]. A Montoya et al. proposed a model where a MOOC was deployed on an OpenEdx platform and was merged with LMS for teaching an undergraduate course which had promising results [16]. A blended model was implemented at Fayoum University, Egypt in collaboration with RWTH Aachen University Germany for a course 'Teaching Methodologies' by using the bMOOC platform L2P-bMOOC [17]. R. G. Utomo et al. in a study blended MOOCs to a university in Indonesia by proposing MOOCs as an alternative to distance learning models to save resources [18]. S. Briggs et al. described how MOOCs can be blended with K-12 Education for students of age up to 19 years [19]. S. Sanchez-Gordon et al. proposed a model for enhancing the productivity of MOOCs for non-native speakers by proposing a blended model that included Non-Native Speaker, local instructors, and MOOC authors, a local non-virtual study group, a content management system, a learning management system, and an adaptive content engine [20]. Diana Andone et al. proposed a blended model for Master level students where asynchronous online course work was integrated with the traditional classroom method [21]. In Germany, Lubeck University of Applied Sciences integrated MOOCs to their curriculum by building their own MOOC platform on an open-source learning management system known as Moodle [22]. Ali Shafaat et al. proposed the reusability of MOOC learning modules for different courses and making the model more projects based to make it more beneficial for both instructor and student in a graduate engineering course [23]. Deepak B. Phatak, proposed a blended model to address various challenges related to MOOCs to combine the college curriculum with MOOCs wherein around $80 \%$ weightage will be given to the score obtained in MOOCs and the role of the institutional teacher is increased and the local teacher will do $15-20 \%$ of evaluation [24].

\section{Curriculum Inclusive MOOCs}

The ciMOOC model was introduced in a private Indian University by choosing a particular course from the National Program on Technology Enhanced Learning (NPTEL) in the Computer Science discipline [5]. A 4 credit course was selected from NPTEL in order to implement and evaluate the performance of ciMOOCs. On the NPTEL platform, courses in Engineering and Physical Science are offered by top institutions across India and instructed by the professors of the same.

The study reported that ciMOOC enhanced the learning of the students and also improved their performances on the MOOC platform. It helped them to prepare themselves for the evaluation of the MOOC platform and by fulfilling the university's assessment scheme, they were also able to gain credits from the university. This helped them getting certification from the MOOC platform for professional growth and further reduced the workload on the students. The university was able to save resources and infrastructure by implementing the ciMOOC for that particular semester.

From the literature review, we found that current trends in research focus on integrating MOOCs with the curriculum to save resources and enhance learning. Studies highlighted 
different methodologies for implementing blended MOOCs and revealed the successful implementation of a ciMOOC. However, in order to know how efficient the ciMOOC was, an in-depth analysis of the learners' perspective to identify whether a blended model proves better than the traditional MOOC is required and forms the basis for this study.

\section{INDICATORS OF PERFORMANCE}

In the ciMOOC, both the university and the MOOC platform conducted performance evaluation. Mid Semester and Final Examination for the course were conducted by the University in accordance with the assessment scheme of the University, and students were able to gain credits for the same. The NPTEL platform evaluated students based on online assignments and the final online examination. A detailed comparison was drawn between the methodologies of the evaluation conducted by the University and the NPTEL platform.

\section{A. Performance Evaluation by the University}

For granting credits to the student in ciMOOC, the university did its evaluation. The evaluation had five major components and continuous assessment was done. The Class test was conducted which was like a mid-semester examination which was for one-hour duration. The test was subjective in nature. Students were also asked to submit a mandatory home assignment. A viva was conducted after the syllabus was completed on the MOOC platform. Five marks were for regularity and attendance of the 15 sessions with the university professor.

The final university exam was a subjective assessment that had the same course curriculum as that being taught on the NPTEL platform. This assessment was divided into three sections which were application based and evaluation of learning outcome for each module was done. After the complete evaluation, the students were given credit scores according to the university's examination policy and passing criterion.

\section{B. Performance Evaluation by the MOOC Platform}



Fig. 1. Comparative of university and MOOC platform evaluation schemes.

For getting the certification for the particular course by the NPTEL platform, the evaluation was done by the platform itself. Students were supposed to send assignments every week. The weightage of assignments was 25 percent and the final examination had a weightage of 75 percent and a student was supposed to score more than 40 percent in total after adding the assignments score and final assessment to complete the course successfully on the platform and get a certification for the same. The final assessment was conducted on the test center and the assessment was objective in nature. If the student scores more than 40 percent he is allotted a certificate of various types according to the NPTEL scheme. A comparative between the University Evaluation Scheme and MOOC platform evaluation scheme is drawn in Fig. 1.

\section{INSTRUMENT DESIGN}

To investigate the usefulness of ciMOOC model and to record the perspective of the learners about ciMOOCs which is one of the major focuses of this study, an instrument was designed. A well-drafted questionnaire about the ciMOOC was prepared. Google forms were used for making this instrument. First, a pilot test was done to confirm the specifications of the instrument created. We emailed our survey to 262 students who choose ciMOOC [5]. We asked our respondents to provide us with their University's enrollment number, their name and were further asked to answer our survey questions based on their experience of the ciMOOC. The data collected was categorical in nature. This instrument was further used to understand in depth the perspective of the learners towards ciMOOCs. The response of only those learners was recorded who opted for ciMOOC during its implementation and completed the course at the university and also earned a certificate at the MOOC platform $[5]$.

\section{ANALYSIS}

The research instrument designed recorded in total 113 responses out of which three were redundant and hence were removed from the final analysis. Hence a total of 110 records were analyzed. The results showed that 88.2 percent of learners believed that this model helped them in clearing the NPTEL certification and only 2.7 percent were not of the same opinion.

Further, it was analyzed that 45.5 percent of learners benefitted from a weekly session with the college professor by clearing their doubts faced in the video lecture of NPTEL. 39.1 percent believed that they were able to learn more from the set of questions provided by the university faculty in those sessions every week. In addition to this 33.6 percent approached their institution faculty if they faced any doubts in MOOC video lectures.

Only 6.4 percent approached MOOC instructors. 41.8 percent said that the approached both the MOOC instructor and the institution faculty. It was interesting to find out that 18.2 percent approached some other resource for clearing their doubts. 66.4 percent of total students agreed that the internal evaluation done by the university helped them to perform better in the final examination conducted by the MOOC platform and in contrast to this 12.7 percent were not of the same opinion.

It was interesting to find out that 78.2 percent of students felt that ciMOOC model reduced the burden of the traditional college curriculum and agreed to the point that they got more time for self-learning because of this model. Only 7.3 percent disagreed with this. 83.6 percent of students felt that this model helped them to understand and learn the subject more 
efficiently whereas only 1.8 percent disagreed with it. 43.6 percent of students were fine with giving to separate examinations i.e. one for gaining credits in college and other for the certification conducted by NPTEL whereas 40.9 percent of them were not fine with giving two separate examinations.

42.7 percent of students pointed out that evaluation by the university were tougher whereas 43.6 percent were not sure about this and 13.6 percent felt that evaluation by the MOOC platform was tougher. Learner's perspectives on ciMOOCs can be visualized in Fig. 2.

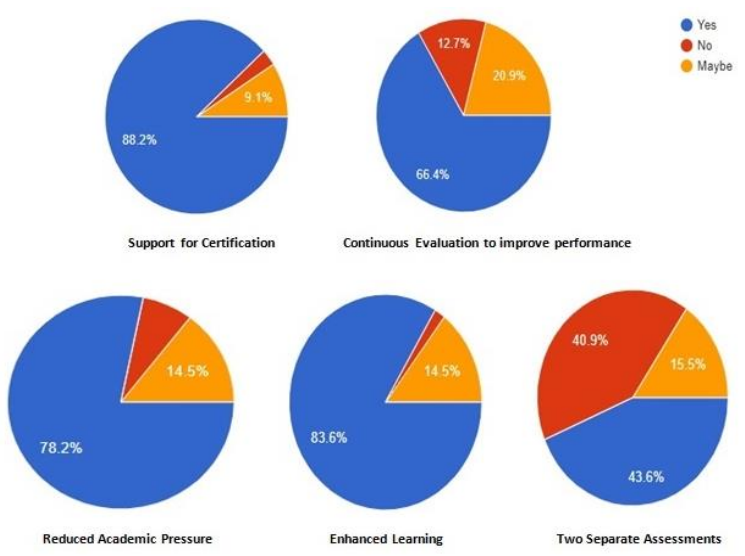

Fig. 2. Learners perspectives on curriculum inclusive MOOC.

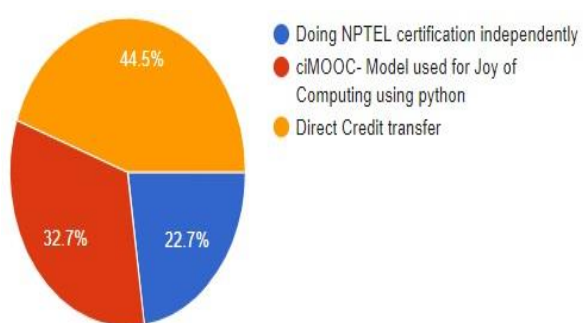

Fig. 3. Learners perspective on choice of MOOC model.



Fig. 4. Performance of students in internal evaluations.

When students were told about another model which is direct credit transfer wherein the students can just do MOOC from the MOOC platform and can get the credit transfer corresponding to the score they obtained on the MOOC platform. $48.2 \%$ of students felt that the direct credit transfer model is better than the ciMOOC model. On the contrary, $21.8 \%$ felt that ciMOOC is better. The results also highlighted that $44.5 \%$ of students were interested in doing MOOCs for direct credit transfer where only $22.7 \%$ were interested in independently doing MOOC. $32.7 \%$ of the students were interested in ciMOOCs. Learner's perspective about the better MOOC model can be visualized in Fig. 3 . Further, we compared the performance of students in the minor evaluation that held 25 percent weightage in the case of MOOC platform and university if we do not include the weightage marks of attendance as it doesn't indicate the measure of learning and understanding of a student for that particular course. The comparison is drawn in Fig. 4.

\section{IMPLICATIONS}

With the help of the research instrument designed for the study, we were able to understand the behavior and response of learners towards the ciMOOC model and also their preference for various MOOC models.

From the analysis, we can infer that learners felt that this model in a way helped them to clear the certification on the MOOC platform. They agreed that the weekly sessions with the university instructor were helpful in solving their doubts and problem. Learners used to interact with both, the university instructor and the MOOC platform instructor for their doubts which helped them to enhance their knowledge of the surface. According to respondents, internal evaluation by the university helped them to perform well on the MOOC platform. We could observe split opinion in the group about acceptance of two separate examinations, one in the university and other at the MOOC platform. Learners felt that the university evaluation was much tougher. Most of them preferred the direct credit transfer model over ciMOOC which they have not experienced so far. Most of them preferred a direct credit transfer model over the conventional MOOCs as well. It was inferred that the curriculum inclusive model gave time for self-learning and was therefore in the interest of the learners.

\section{CONCLUSION}

The study highlighted a model for integrating the regular classroom with MOOCs and perceptions about the same. We were able to identify the gaps by an effective literature review in the domain of merging the MOOCs with the regular university curriculum. We were able to analyze and draw a comparative between the method of evaluation by the MOOC platform and the university in the case of ciMOOCs.

The focus of our study was a detailed analysis of a blended model and therefore could not explore the perceptions related to direct credit transfer. However, it would be interesting to compare the option of direct credit transfer from a traditional MOOC to a blended form. In the future, we may offer direct credit transfer and ciMOOC to the same set of students and then analyze their experience of both the models to understand which method of MOOC is a preferred choice.

We may also investigate the effect of ciMOOCs for various non-engineering courses to better understand the implications. The perspective of the MOOC instructor, University professors, and University administration towards blended models may be further recorded in addition to the learner's perspectives to formulate a framework that would facilitate and support blended learning.

\section{CONFLICT OF INTEREST}

The work was carried without any conflict of interest.

AUTHOR CONTRIBUTIONS 
All authors contributed equally in this work.

\section{ACKNOWLEDGMENT}

Authors would like to express gratitude to Amity University Uttar Pradesh, India for support in conduct of the research.

\section{REFERENCES}

[1] K. Pretz, "10 technologies that could change the world by 2022," IEEE - The Institute, 12 November 2014

[2] M. Waldrop, "Campus 2.0," Nature, vol. 495, no. 7440, pp. 160-163, 2013.

[3] A. Bralić and B. Divjak, "Integrating MOOCs in traditionally taught courses: Achieving learning outcomes with blended learning," International Journal of Educational Technology in Higher Education, vol. 15, no. 2, pp. 1-16, 2018.

[4] "Swayam Central," Swayam Central. [Online]. Available: https://swayam.gov.in/

[5] A. Shrivastava, N. Hasteer, and K. M. Soni, "Perspectives on curriculum inclusive MOOCs for engineering education: Reflection \& learning," in Proc. 2019 IEEE Tenth International Conference on Technology for Education (T4E), 2019, pp. 34-37.

[6] Nptel, online courses and certification, Learn for free. Nptel, Online Courses and Certification, Learn for Free. [Online]. Available: https://nptel.ac.in/

[7] W. Al-Rahmi, A. Aldraiweesh, N. Yahaya, and Y. B. Kamin, "Massive open online courses (MOOCS): Systematic literature review in Malaysian higher education," International Journal of Engineering \& Technology, vol. 7, no. 4, pp. 2197, 2018.

[8] R. Chakravarty and J. Kaur, "MOOCs in India: Yet to shine," International Journal of Information Studies and Libraries, vol. 1, no. 1, pp. 14-21, 2016.

[9] L. Albo, D. L. Hernández, and M. Oliver, "Blended MOOCs: University teachers' perspective," in Proc. Trends in Digital Education Selected Papers from EC-TEL 2015 Workshops CHANGEE, WAPLA, and HybridEd, 2015, pp. 11-15.

[10] T. Alghamdi, W. Hall, and D. Millard, "A classification of how MOOCs are used for blended learning," in Proc. the 2019 4th International Conference on Information and Education Innovations ICIEI 2019, July, 2019, pp. 1-7.

[11] Y. Li, J. Sun, and M. Sun, "Analysis of the development status and impact of MOOCs in American higher education," Educational Sciences: Theory \& Practice, vol. 18, no. 6, pp. 3442-3448, 2018.

[12] S. Iqbal, X. Zang, Y. Zhu, Y. Y. Chen, and J. Zhao, "On the impact of MOOCs on engineering education," in Proc. 2014 IEEE International Conference on MOOC, Innovation and Technology in Education (MITE), 2014, pp. 101-104.

[13] T. Onink, "Georgia tech, udacity shock higher ed with $\$ 7,000$ degree," Forbes, 2014.

[14] J. Kay, P. Reimann, E. Diebold, and B. Kummerfeld, "MOOCs: So many learners, so much potential ...," IEEE Intelligent Systems, vol. 28 , no. 3, pp. 70-77, 2013.

[15] T. Brahimi and A. Sarirete, "Learning outside the classroom through MOOCs," Computers in Human Behavior, vol. 51, pp. 604-609, 2015.

[16] A. Montoya and P. Ochoa-Botache, "A new approach in blended teaching combining LMS, MOOCs, and piazza for university courses," in Proc. 2018 Learning With MOOCS (LWMOOCS), 2018, pp. 74-77.

[17] A. M. F. Yousef, M. A. Chatti, U. Schroeder, and M. Wosnitza, "A usability evaluation of a blended MOOC environment: An experimental case study," The International Review of Research in Open and Distributed Learning, vol. 16, no. 2, pp. 69-93, 2015.

[18] R. G. Utomo and Y. Rosmansyah, "MOOCs as an alternative to distance learning model for University in Indonesia," in Proc. 2014 International Conference on ICT For Smart Society (ICISS), 2014, pp. 182-184.

[19] S. Briggs and H. Crompton, "Taking advantage of MOOCs in K-12 education," Online Course Management, pp. 1189-1201, 2018.

[20] S. Sanchez-Gordon and S. Lujan-Mora, "Accessible blended learning for non-native speakers using MOOCs," in Proc. 2015 International
Conference on Interactive Collaborative and Blended Learning (ICBL), 2015, pp. 5853-5862.

[21] D. Andone and V. Mihaescu, "Blending MOOCs into higher education courses - A case study," in Proc. 2018 Learning with MOOCS (LWMOOCS), 2018, pp. 134-136.

[22] A. Lorenz, A. Wittke, T. Muschal, and F. Steinert, "From MOODLE to MOOIN: Development of a MOOC platform," in Proc. the European MOOC Stakeholder Summit 2015, 2015, pp. 102-106.

[23] A. Shafaat, F. Marbouti, and K. Rodgers, "Utilizing MOOCs for blended learning in higher education," in Proc. 2014 IEEE Frontiers in Education Conference, 2014, pp 1-4.

[24] D. B. Phatak, "Adopting MOOCs for quality engineering education in India," in Proc. the International Conference on Transformations in Engineering Education, 2014, pp. 11-23.

Copyright $\odot 2021$ by the authors. This is an open access article distributed under the Creative Commons Attribution License which permits unrestricted use, distribution, and reproduction in any medium, provided the original work is properly cited (CC BY 4.0).

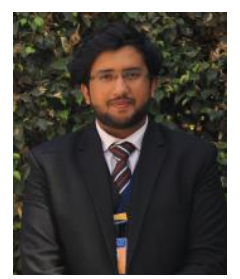

Aakarsh Shrivastava was born on 28 September 1996 in Kanpur, India. He is currently a final year student of Amity School of Engineering and Technology, Amity University, India where he is pursuing the bachelors in technology with majoring in information technology. $\mathrm{He}$ is also working with McKinley and Rice as a full stack developer.

$\mathrm{He}$ is skilled in tech security, web application development and blockchain. He has completed more than 10 MOOCs from different MOOC platforms with in total 6 from NPTEL India because of which he has a great experience regarding different MOOC platforms. His most recent work is Perspectives on Curriculum Inclusive MOOCs for Engineering Education: Reflection \& Learning.



Nitasha Hasteer has twenty years of cross-cultural experience in industry and academia working with leading organizations in India and Japan. She holds a graduation, masters and doctorate degree in Computer Science \& Engineering. She is currently working as Dy. Director - Academics at Amity School of Engineering \& Technology, Amity University Uttar Pradesh, India. Her research interests include software process modeling, project-based learning \& management and latest advancements in the field of Education \& Information Technology. She has contributed over 40 research papers in refereed conferences and journals. She has chaired technical sessions in her areas of interest and has served as reviewer \& programme committee member at many National \& International Conferences in India and abroad. She is a member of many professional bodies including IET (UK), IEEE(USA), IACSIT, IETE and Computer Society of India.

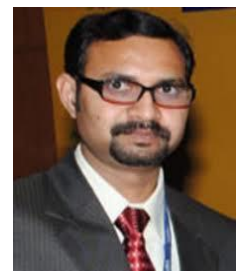

K. M. Soni did his B. E. in electrical engineering \& M.E. in control \& instrumentation from Motilal Nehru National Institute of Technology, Allahabad, India \& $\mathrm{PhD}$ in electrical engineering from Jamia Millia Islamia (A central University), New Delhi, India. Dr. Soni is a professor in Amity School of Engineering \& Technology, Dy. Dean (Engg. \& Tech.), and also in-charge of Ph.D. programmes in AUUP. He is the author of books on circuits and systems, signals and systems, basic system analysis, network analysis and synthesis and advanced control systems etc. Also, He is author/co-author of over 25 technical research papers in refereed conferences and journals and served as reviewer, programme committee member, session chair of many national \& international conferences in India and abroad, and also served as reviewer of several journals. He is life member of Indian Society for Technical Education (ISTE), Institution for Electronics and Telecommunication Engineers (IETE), International Journal of Engineering Research and Industrial Applications (IJERIA), CSI, IET (U.K.), IEEE, IUCEE, and other similar organizations. His current research interests are in power electronics, power system, advanced control systems, signal processing, educational technology, and other related areas. 